\title{
SOBERANO, NORMAS E SANÇÕES EM JEREMY BENTHAM
}

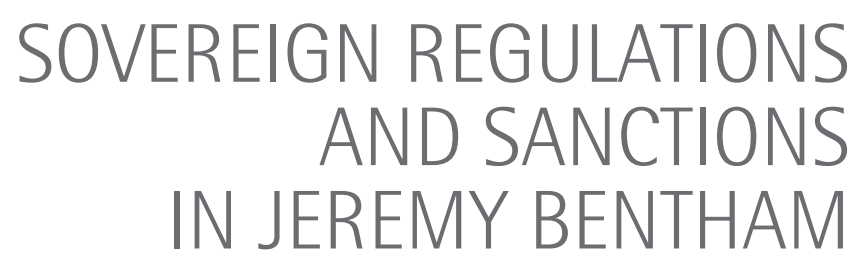

Adrian Sgarbi

adriansgarbi@gmail.com

Recebido: 4-3-2018

Aprovado: 19-8-2020

Sumário: Introdução; 1. Dois sentidos para teoria do direito; 2. O princípios da utilidade e o cálculo da felicidade; 3. Ação humana; 4. O soberano e a sua supremacia; 5 . O soberano e a origem das leis; 6 . As normas costumeiras; 7. As normas jurídicas e o common law; 8. Sobre as modalidades prescritivas; 9. O Papel central da sanção; 10. Conclusão. Referências bibliográficas.

\section{Resumo:}

Fundador do utilitarismo, jurista e defensor da codificação, Jeremy Bentham foi teórico, filósofo e se ocupou da política. Autor que inaugurou um método largamente utilizado pela filosofia analítica, Bentham está na raiz do pensamento jurídico de muitos autores contemporâneos. O objetivo deste ensaio é apresentar alguns dos lineamentos da teoria do direito de Bentham. Para tanto, nos concentraremos nas noçóes de a) soberano, b) normas e c) sançóes. Como pontos de apoio, faremos referências (preliminares) ao significado de "teoria do direito" e "principio da utilidade".

\section{Palavras-chave:}

Jeremy Bentham; utilitarismo; normas; teoria do direito.

\section{Abstract:}

Founder of the utilitarianism, lawyer and an advocate of codification, Jeremy Bentham was an theorist, philosopher and involved in politics. An author that inaugurated a widely used method by the Analytic philosophy, Bentham is on the root of the legal thought of many contemporary authors. The objective of this essay is to present some of the outlines of the Bentham's legal theory. Therefore, we will concentrate on the notions of a) sovereign, b)legal standards, c)criminal sanctions. To support our essay we will make (preliminary) references to the meaning of "legal theory" and "the principle of utility".

\section{Keywords:}

Jeremy Bentham; utilitarism; norms; legal theory. 


\section{INTRODUÇÃO}

Fundador do utilitarismo, jurista e defensor da codificação, Jeremy Bentham foi teórico, filósofo e se ocupou da política. Autor que inaugurou um método largamente utilizado pela filosofia analítica, Bentham está na raiz do pensamento jurídico de muitos autores contemporâneos.

De fato, pode-se dizer que é o jurista que encabeça o positivismo jurídico inglês, nascido certamente com as contribuições da filosofia política de Hobbes, mas que apenas com John Austin mereceu o título de Analytical School of Jurisprudence e com Herbert L. A. Hart teve seu lugar de debate na teoria jurídica do século XX (Hart, 2001, p. 21-39). Entretanto, a tarefa assumida por Bentham, de certa maneira, foi mais ampla e demolidora do que a de Austin (e mais pretensiosa do que a do próprio Hart), pois o autor não se manteve adstrito à teoria do direito, porquanto se ocupou fortemente da teoria da legislação, ou, como designou, da nomografia.

O objetivo deste ensaio é apresentar alguns dos lineamentos da teoria do direito de Bentham. Para tanto, nos concentraremos nas noçóes de a) soberano, b) normas e c) sançóes. Como pontos de apoio, faremos referências (preliminares) ao significado de "teoria do direito" e "principio da utilidade".

\section{DOIS SENTIDOS PARA A TEORIA DO DIREITO}

Nas Notas de Conclusão, capítulo XVII de An Introduction to the Principles of Moral and Legislation, Bentham resume a sua compreensão a respeito da "teoria do direito" (jurisprudence). Para ele, com a expressão "teoria do direito" expressam-se, um tanto confusamente, dois conceitos que devem ser distinguidos: por um lado, a doutrina "expositiva" (ingl. expositori); por outro, a doutrina "crítica" (ingl. censori) (Bentham, 2005, p. 294-295).

Por definição, assim entende Bentham, a "doutrina expositiva” trata da descrição do direito tal como ele é; já a "doutrina crítica” cuida do direito como ele deve ser.

Em atenção à doutrina expositiva, afirma que a tarefa a ser cumprida está dividida em duas partes: 1) na "exposição histórica" do Direito e 2) na "simples exposição".

A primeira, trata do direito tal qual fora concebido em épocas passadas; a segunda, consiste em apresentar ou descrever o direito como ele é na atualidade, mediante técnicas de sistematização, narração e conjetura.

No livro Um Fragmento sobre o Governo, Bentham expõe uma afirmação enfática:

Há duas posturas que se pode dizer que qualquer homem que tenha algo a dizer sobre o Direito deve levar em consideração: a do Expositor e o do Censor. Concerne a postura de Expositor dizer como ele supóe que é o direito; a de Censor, ensinar-nos o que se crê que ele deva ser. A primeira se preocupa principalmente em estabelecer, ou investigar, os fatos; a última, em discutir as razóes. O Expositor, mantendo-se em sua esfera de atuação, não tem relação com nenhuma das faculdades da mente que não seja a apreensão, a memória, e o juízo; o Censor, em virtude daqueles sentimentos de prazer ou desagrado que encontre ocasião para uni-los aos objetos sob sua consideração, mantém alguma relação com os afetos (...). O Expositor é sempre o cidadão deste ou daquele país em particular; o Censor é - ou deve ser - o cidadão do 
mundo. Ao Expositor compete mostrar o que o Legislador e o Juiz tem feito; ao Censor lhe cabe sugerir o que o Legislador deve fazer no futuro (Bentham, 2003, p. 10-11).

A propósito, no que diz respeito à "doutrina expositiva", ainda se refere à "teoria do direito local" e à "teoria do direito global".

Por "teoria do direito local" (local jurisprudence), designa o direito positivo de um determinado país; e por "teoria do direito global" (universal jurisprudence), refere à teoria do direito de todas as naçóes.

Pontua ademais Bentham que o "objeto da teoria do direito" - ou uma de suas tarefas principais - é a de assentar os conceitos jurídicos fundamentais. A determinação desses conceitos, por sua vez, é realizada através de detido estudo linguístico. Ou seja, a teoria do direito deve reduzir-se à análise da definição das palavras e expressóes que nos diversos idiomas mantêm certa correspondência, tais como "lei", "poder", "direito subjetivo", "obrigação" e "liberdade".

Em que pese esta redução, está evidente na construção de Bentham algo mais que a análise de terminologias, pois, sobretudo em Sobre as Leis em Geral, nota-se consistente exame sobre a estrutura das ordens jurídicas (Bentham, 1970, capítulos II e III).

Em síntese, segundo Bentham, a "teoria do direito" pode ser triplamente referida 1) como "doutrina expositiva" e como "doutrina censória"; 2) como "doutrina dotada de autoridade" e como "doutrina náo dotada de autoridade"; e, finalmente, 3) como "teoria do direito global" e como "teoria do direito local".

\section{2.. 0 "PRINCÍPIO DA UTILIDADE" E 0 "CÁLCULO DA FELICIDADE"}

$\mathrm{Na}$ raiz do pensamento de Bentham, encontra-se a ideia, expressa em Uma Introdução aos Princípios da Moral e da Legislação, segundo a qual o ser humano é governado pelos ditames do prazer e da dor. E são estes ditames que auxiliam na percepção dos motivos pelos quais obedecemos às regras produzidas pelo "legislador". Segundo Bentham,

“a natureza colocou o gênero humano sob o domínio de dois senhores: a dor e o prazer. Somente a eles compete apontar o que devemos fazer, bem como determinar o que na realidade faremos. Ao trono desses dois senhores está vinculada, por uma parte, a norma que distingue o que é reto do que é errado; e, por outra, a cadeia das causas e dos efeitos" (Bentham, 2005, p. 11).

O objetivo a ser alcançado com o reconhecimento deste princípio é o de "construir o edifício da felicidade através da razão e da lei” (Bentham, 2005, p. 11-12).

Portanto, são cruciais, neste primeiro momento, para se bem entender o pensamento de Bentham, a) o "princípio da utilidade", b) o termo "utilidade" e c) a "correção" (ou "moralidade").

(1) "Princípio da utilidade": deve-se aprovar ou desaprovar qualquer ação segundo a tendência de aumentar ou diminuir a felicidade da pessoa cujo interesse está em jogo.

(2) "Utilidade": propriedade existente em qualquer coisa em virtude da qual o objeto tende a produzir ou proporcionar benefício, vantagem, prazer, bem ou 
felicidade ou a impedir que aconteça o dano, a dor, o mal, ou a infelicidade para a parte cujo interesse está em pauta.

(3) "Correção" ("ou moralidade"): a correção de uma ação se mede pelos seus resultados.

Observe-se que os referidos "dois senhores" aparecem no pensamento de Bentham, de forma matizada, em diversos momentos do seu trabalho (Dinwiddy, 2004, 134-135). Por exemplo, em sua teoria do governo, revelam-se entrelaçados a aspectos psicológicos, dado que o homem tende a atuar segundo os seus próprios interesses; interesses esses que novamente são considerados em termos de prazer e de dor.

O cálculo da felicidade, neste contexto, é um algoritmo formulado por Bentham para medir a quantidade de felicidade que uma ação específica pode causar. Através do seu uso, cogita a possibilidade de o cálculo servir de base à melhor decisão moral. As variáveis, ou os vetores dos prazeres e das dores nele incluídas - que Bentham chamou de "elementos" ou "dimensôes" (Bentham, 2005, p. 38-39) - são:
(1) Intensidade.
(2) Duração.
(3) Certeza ou incerteza.
(4) Proximidade física ou distância.

Segundo Bentham, para estimar o ato que origina esse prazer ou dor, deve-se considerar outras circunstâncias:

(5) Fecundidade: a probabilidade de o ato ser seguido por sensaçóes de mesmo tipo.

(6) Pureza: a probabilidade de o ato ser seguido por sensaçóes de tipo oposto.

Já para calcular o valor de um prazer ou dor deve ser considerada, ainda, a:

\section{(7) Extensão.}

Entre os usos possíveis desse cálculo, afirma, encontra-se a possibilidade de medir o desempenho de um governo considerando que "uma medida do governo está em conformidade com o princípio da utilidade quando a tendência que tem a aumentar a felicidade da comunidade for maior do que qualquer tendência que tenha a diminuí-la" (Bentham, 2005, p. 12). Ou seja, o governo é avaliado conforme as suas realizaçóes tendo em vista que "a missão dos governantes consiste em promover a felicidade da sociedade, punindo e recompensando” (Bentham, 2005, p. 19).

Além disso, pode-se extrair importante consequência: as obrigaçóes apenas fazem sentido quando apoiadas por alguma forma de sanção ou punição dado que essas são elementos relevantes para a determinação dos comportamentos e, por conseguinte, do seu emprego adequado ou inadequado pelo governo. Significa dizer que Bentham, e, depois dele, sobretudo John Austin e Hans Kelsen, entende haver certos elementos caracterizadores das normas jurídicas como tais. 


\section{AÇÃO HUMANA}

Como referido, o princípio básico da formulação de Bentham é a noção de prazer e de dor como elementos (ou como "senhores") atuantes na vontade. Fundamentalmente, "prazer" é a sensação preferida em relação a nenhuma sensação; e "dor" é a sensação que se prefere não ter a se ter alguma. Sentir prazer e escapar ou fugir da dor são sensaçóes que estão nos alicerces da construção do autor.

Bentham entende que a ação humana se expressa no movimento realizado pela vontade de um agente acerca de um prazer que este nutre a expectativa de obter. Sendo assim, ação humana e vontade mantêm relação imediata. $\mathrm{O}$ indivíduo, quando atua, procura realizar a ação que lhe proporcione maior felicidade.

Além disso, ação humana e vontade apresentam um conteúdo social evidente. Isso porque "uma pessoa é partidária do princípio da utilidade quando a aprovação ou a desaprovação que dá a alguma ação, ou a alguma medida, for determinada pela tendência que, no seu entender, tal ação ou medida tem a aumentar ou a diminuir a felicidade da comunidade" (Bentham, 2005, p. 13).

A vontade, portanto, determina a atuação em razão de um desejo que a póe em marcha. Tal desejo, por sua vez, é originário de uma situação concreta ou potencial capaz de instigar a realização de uma ação ou de evitá-la, isto é, configura um "motivo". Por "motivo", assim define Bentham, deve-se entender "qualquer coisa que, influenciando a vontade de um ser sensível, se supóe servir como meio de determiná-lo a agir, ou voluntariamente deixar de agir, em qualquer determinada ocasiáo" (Bentham, 2005, p. 96). Esses motivos são "materiais" ou "práticos", e, como tais, diferem dos especulativos, porquanto estes se mantêm adstritos apenas à mente, e não ao corpo.

No entanto, o termo "motivo", apesar das precisōes anteriores, sofre de forte instabilidade linguística, segundo o próprio Bentham. Por isso, pode-se falar em sentido "não-figurado" e sentido "figurado" da palavra "motivo".

Por sentido "não-figurado" (ou literal), "motivo" se refere aos fatores empíricos dos quais se supóe que o ato se origina; por sentido "figurado" (ou fictício), entende-se um ser ideal, um estado da mente, uma paixão que exerce influência sobre a mente e a dispóe a tomar decisões, tais como a avareza, a indolência, a benevolência e outros.

Os motivos são "em perspectiva" ou "in esse". Tanto um como outro podem decorrer de uma percepção interna como de um evento externo.

O primeiro refere-se a um acontecimento possível, mas ainda não existente; o segundo, está relacionado ao objeto presente ou evento que se realiza.

Depois de estabelecer essas considerações, Bentham é enfático ao afirmar que nada tem a sua obra a ver com os motivos cuja influência termina na inteligência. Por essa razão, quando se exige, as razóes de um ato são aquelas que originaram uma prática (Bentham, 2005, p. 98).

A ação humana que tende a aumentar a felicidade, diz Bentham, orienta-se de acordo com o princípio da utilidade. De maneira que associar o dever ao prazer auxilia na atribuição de sentido a palavras como "deveria", "reto", "errado", o mesmo valendo para termos análogos. Porque em relação a uma ação que está conforme ao princípio da utilidade, pode-se sempre afirmar que "ela deve ser praticada, ou, no mínimo, que não é proibido praticá-la”. Mas questiona Bentham se ela é passível de alguma demonstração direta, esta é a resposta que fornece à conjetura: "Parece que não. Com efeito, o princípio que se utiliza para demonstrar todas as outras coisas não pode ele mesmo ser demonstrado; uma cadeia 
de demonstraçóes deve ter o seu início em algum ponto. Consequentemente, fornecer esta demonstração é tão impossível quanto supérfluo" (Bentham, 2005, p. 13).

\section{O SOBERANO E A SUA SUPREMACIA}

No já referido Um Fragmento sobre o Governo, Bentham define "sociedade política" da seguinte forma: "Quando certo número de pessoas (que podemos denominar de súditos) tem o hábito de obedecer a uma pessoa ou a uma assembléia de pessoas que reúnem certas características (e que podemos chamar de governante ou governantes), o conjunto deles (súditos e soberanos) vive em um estado de sociedade política” (Bentham, 2003, p. 467).

À vista disso, podem-se agregar estas observaçóes:

(1) Distinção entre "sociedade política" e "sociedade natural": é o hábito de obediência dos súditos em relação ao governante ou governantes (soberano) que extrema esta sociedade política da sociedade natural.

(2) "Identificação" do "soberano": o soberano é, para Bentham, “... a pessoa ou assembléia de pessoas cuja vontade uma sociedade política está disposta (não importa por qual motivo) a obedecer antes de qualquer outra pessoa".

(3) "Facticidade" do "poder" do soberano: o poder do soberano decorre, simplesmente, da situação social de este ser obedecido pelos súditos. Portanto, seu caráter de "ser soberano" é empiricamente verificável.

(4) "Utilidade": considerando-se ser, para Bentham, o princípio da utilidade aquele que o soberano deve promover a partir das leis que produz, a obediência ao soberano mantém relação com certo imperativo da consciência dos indivíduos em promoverem esta felicidade. Com isso, está afastada qualquer consideração jusnaturalista da lógica da obediência ao soberano, porquanto ela decorre de um princípio ético positivo, isto é, a maximização da felicidade coletiva.

Considerando os precedentes itens (1), (2), (3) e (4), deve-se pontuar que uma norma é jurídica se é relativa a um soberano. E por soberano - assim afirma Bentham - deve-se entender "... uma pessoa ou um conjunto de pessoas cuja vontade se supõe que uma inteira comunidade política esteja disposta (não importa por qual motivo) a prestar obediência; e, isto, preferencialmente a qualquer outra pessoa" (Bentham, 1970, p. 18).

Ademais, nota-se nas palavras do jurista forte compromisso sociológico-empírico, tendo em vista que conjuga os aspectos da obediência com a preferência de obediência a um agente em particular, isto é, ao soberano. Portanto, a obediência preferencial e fática é que qualifica alguém como soberano; isto independentemente dos motivos encontrados para que essa preferência se concretize.

Sendo assim, o poder normativo do soberano é um "poder" normativo de fato, dado que não nascido de qualquer norma jurídica. Por outras palavras, o status de soberano depende da sua capacidade de influir na vontade dos membros da comunidade política examinada. Assevera o autor:

É evidente que o poder de fato, a soberania sobre qualquer indivíduo determinado, pode configurar-se de maneiras muito diversas e em contínua flutuação. [Isso porque] 
a sua persistência depende de mil fatores acidentais. Faticamente, um homem está sujeito àquele soberano que esteja em grau de fazê-lo sofrer: na pessoa (vale dizer, no corpo ou na mente), na reputação, nos bens, ou na condição (Bentham, 1970, p. 20).

Tudo isso se dá porque, na teoria de Bentham, o soberano é soberano, ou seja, ele é o agente superior na comunidade. Aliás, nenhuma ordem sua pode ser considerada ilegal, pois sua lei "pode ser cruel, pode ser apolítica, pode ser inconstitucional: porém não pode ser ilegal” (Bentham, 1970, p. 16-17). Isso significa que uma determinação pode ser contrastante com a constituição do país, mas nem assim deixará de ser lei.

Mas não indica que o soberano não esteja submetido a qualquer lei. Daí o autor distinguir as leis quanto aos destinatários e quanto ao soberano: quanto aos destinatários elas são laws in populum; já quanto ao soberano, são leis por princípio (laws in principem). Estas leis, isto é, as "leis por princípio", são as que o próprio soberano edita para si mesmo e para o seu sucessor, de modo que soam como pactos desse para com os seus súditos (Bentham, 1970, p. 64-65). Como pactos, elas possuem apenas repercussão moral para o soberano; assim, não são "verdadeiramente leis". Isso se deve à situação de ser impossível, no que toca ao soberano, recorrer à outra força que não a sua própria (caso contrário ele náo seria soberano, pois estaria evidente a sua submissão a outra instância de poder diferente dele mesmo). Desse modo, a razão que o soberano encontra para obedecer a essas leis é a pura conveniência do seu ato.

Em resumo, o soberano de Bentham 1) detém o poder normativo por uma origem fática, 2) esta origem fática se resume à propensão de o soberano ser obedecido preferencialmente em relaçáo a qualquer outra pessoa ou agente e 3) nessa obediência, náo figura qualquer razão moral necessária.

\section{O SOBERANO E A ORIGEM DAS LEIS}

Segundo Bentham, o soberano é a origem de todas as normas jurídicas da comunidade política que está submetida às suas normas.

Entretanto, o soberano não é a origem direta de todas as normas jurídicas da comunidade política, uma vez que o autor as subdivide em 1) normas concebidas ou normas soberanas; e 2) normas adotadas ou normas subordinadas.

Nestes termos:

(1) "Normas concebidas": são normas que foram produzidas diretamente pelo soberano.

(2) "Normas adotadas": são normas que, embora não produzidas diretamente pelo soberano, são por ele validadas.

Ou seja, por definição, as normas "adotadas" são todas aquelas que foram produzidas por agentes outros que não o soberano. Tal possibilidade de atribuir poderes é intrínseca à qualidade de "ser soberano" e está compreendida em seu poder de legislar. Assim, o poder de legislar é um poder que, em relação ao indivíduo, exerce um efeito de agregação (power of aggregation) ou de associação (accensitive power). Quando este "poder de legislar", por sua vez, constitui uma atribuição de poder a determinados indivíduos, ele passa a ser denominado por Bentham de "poder de investidura" (investive power). 
Quanto às normas não produzidas pelo soberano, ao autor as examina sob quatro focos de atenção: 1) temporal, 2) pessoal, 3) força e 4) forma.

Portanto:

(1) "Temporal": diz respeito ao momento em que a adoção é realizada pelo soberano. A adoção realizada pelo soberano pode ser sucessiva (ou ex post) ou preventiva (ou ex ante) em relaçáo à norma adotada.

(2) "Pessoal": é tangente aos sujeitos que originariamente produziram a norma.

(3) "Força": concerne ao grau ou intensidade que a norma produzida adquire em razão de sua adoção.

(4) "Forma": corresponde à modalidade da adoção procedida pelo soberano.

Quanto ao primeiro foco, o "temporal", como pontuado, afirma Bentham que as normas adotadas podem ser analisadas - sempre em atenção ao momento em que o soberano a adota - tanto sucessiva quanto preventivamente à sua efetiva produção.

A "adoção sucessiva” tem por objeto normas já produzidas, seja pelo soberano precedente, seja pelos seus agentes delegados. A adoção pode ser tanto "expressa" quanto "tácita”. Adoção "expressa” se dá quando, havendo dúvida a respeito da sua adoção ou não, o soberano emana uma "norma de recepção". Neste caso, ela será, apenas, iterativa. Adoção "tácita” ocorre quando o soberano tão-somente não produz qualquer norma incompatível com aquela produzida pelo seu predecessor ou pelos subordinados.

A "adoção preventiva", por sua vez, tem por objeto a atribuição de um poder normativo a certos agentes (indivíduos ou classe de indivíduos, diz Bentham), os quais, com a atribuição deferida, atuam como origem subordinada de normas. Portanto, através dos atos dos agentes subordinados, o soberano autoriza normas delegadas.

Quanto ao segundo foco, "pessoal”, isto é, quando estão em consideração os sujeitos que efetivamente produziram a norma, Bentham faz menção a duas razões da delegação: a) a título de benefício ou b) a título de fidúcia.

(a) "Adoção preventiva a título de benefício": trata-se de produção normativa delegada que se exerce para atender exclusivo interesse daquele ou daqueles que o exercem (p. ex.: os contratos privados).

(b) "Adoção preventiva a título de fidúcia": refere-se ao poder normativo que se exerce no interesse de terceiros (p. ex.: em nome dos menores de idade).

Bentham, no entanto, afirma que, quanto ao caso (b), isto é, na adoção preventiva a título de fidúcia, essa pode ser um poder fiduciário "privado" (quando o objetivo são interesses privados) ou ser um poder fiduciário público (quando o objetivo forem interesses da comunidade política em seu complexo).

Quanto ao terceiro foco, "força”, ou seja, ao grau de intensidade que a norma adquire a partir do momento em que é adotada pelo soberano, pode variar da "nua permissão" até a "permissão máxima” (Bentham, 1970, p. 22-23).

Por "nua permissão" entende Bentham aquela que decorre da simples ausência de prescrição. Dessa maneira, a conduta que não é proibida pelo soberano é permitida, sendo decorrência da postura "puramente negativa” do soberano. A base para essa afirmação é que, caso assim o desejasse, o soberano poderia vetar o comportamento se isso estivesse de acordo 
com a sua vontade ou as suas pretensóes. Quando não o faz, significa que autorizou o ato implicitamente.

Por "permissão máxima” alude à permissão que é estatuída expressamente por um ato do soberano, isto é, manifestada de modo explícito.

Quanto ao quarto e último foco, "forma", significa dizer a modalidade de adoção da norma adotada pelo soberano, se refere a três hipóteses ou situaçóes: 1) a permissão "implícita", 2) a permissão "explícita" e 3) a produção de uma "norma imperativa" (Bentham, 1970, p. 23). Os casos 1 e 2 se identificam com as situaçóes de "nua permissão" (isto é, o soberano permite apenas por omitir proibir quando poderia fazê-lo) e "permissão máxima” ("o soberano diz expressamente a quem está permitido produzir a norma”); já o caso 3 equipara-se à determinação do soberano que seja obedecida uma norma produzida por um agente por ele indicado. Como pode ser inferido, os números 2 e 3 são situaçóes de atribuição de competência da parte do soberano para algum agente ou agentes.

\section{AS NORMAS COSTUMEIRAS}

Para Bentham, a noção de costume está relacionada, sem dúvida, à de hábito, ou seja, à existência de comportamentos repetidos que geram expectativas a respeito das açóes humanas futuras possíveis. Entretanto, não é esse aspecto que o dota de autoridade “jurídica”. Porque para ser "jurídica" é imprescindível o reconhecimento oficial do comportamento habitual como devido, e tal ocorre, apenas, quando uma sanção é agregada ao costume na situação de desobediência.

Conforme indica, no modelo Common Law, esta autoridade está presente nos costumes, sobretudo, após ter-se o resultado de uma ação jurídica, porque singularmente é nesse momento que a sanção aparece como mecanismo de apoio. A questão é que o processo gera apenas normas individuais, de maneira que é problemática a concepção de uma ordem jurídica baseada "apenas" nos costumes. Portanto, para o bem da ordem social, deve-se cogitar uma autoridade soberana que seja fonte do direito e que, assim, edite normas gerais.

Considerando as bases da formulação, tem-se, complementarmente, em Um Fragmento sobre o Governo, certo esforço classificatório.

Segundo Bentham, os costumes podem ser considerados:

(a) Em razão das pessoas: a1) costumes "sociais" os quais decorrem da regularidade de conduta de um segmento da sociedade e a2) costumes "judiciais" cuja origem é a regularidade da conduta dos juízes.

(b) Quanto à origem: b1) “espontâneos" são aqueles que surgem dos comportamentos sociais e b2) "produzidos pelo direito" são os costumes que se originam da observação geral do que decidem os juízes.

(c) Em atenção ao reconhecimento: c1) "legalizados" são os costumes reconhecidos como habituais pelo parlamento ou pelos juízes e c2) "não-legalizados", os que se encontram apenas adstritos à prática geral antes de qualquer reconhecimento de alguma autoridade.

Atentando-se para os itens (a), (b) e (c), nota-se o "divisor de águas" da atuação da autoridade como ponto de ancoragem do catálogo de Bentham. Esse aspecto está relacionado, 
como assinalado, à importância que atribui Bentham às sançóes na caracterização das obrigaçôes jurídicas como "jurídicas”.

\section{AS NORMAS JURÍDICAS E O COMMON LAW}

As normas jurídicas, para Bentham, são instrumento de maximização do bemestar, tendo em vista que através delas busca-se a coordenação das expectativas, de modo a proporcionar a felicidade dos indivíduos. Dessa maneira, como diretivas, as normas assentam comportamentos, e os indivíduos, ao seguirem o direito, tornam possível a promoção da felicidade para o maior número de pessoas.

No entanto, deve-se pontuar que a ideia de norma náo é uma reconstrução do direito mesmo, mas um ideal que seria alcançado quando o direito da Inglaterra se tornasse direito legislado. Isso porque, o fundamento da doutrina inglesa é o Common Law e o Case Law, de maneira que é o direito judicial, conjuntamente com os precedentes, a referência jurídica máxima. Sustenta, enfaticamente, no prefácio de Uma Introdução aos Princípios da Moral e da Legislação:

O Common Law, como denominado na Inglaterra, o Direito judicial, como poderia ser chamado em melhor designação, àquela composição ficcional que náo tem pessoa alguma como autor, nem um conjunto conhecido de palavras por substância, forma o composto principal da fábrica jurídica: como aquele ilusório éter que, na falta de matéria sensível, enche o universo. Fragmentos e tiras da lei real, unidos por aquele fundamento imaginário, compóem o mobiliário de todo código nacional (Bentham, 2005, p. 8).

Neste passo, evidencia-se o projeto de Bentham, pois seu desejo é erigir um corpo de legislação que faça nascer uma ordem social pautada no princípio da utilidade.

A este respeito, um dos principais aportes críticos de Bentham está relacionado ao próprio modelo inglês em relação às ações individuais de conduta. Entende que o Common Law não serve satisfatoriamente como guia para as açóes humanas, pois o modelo não é adequado como referência racional para condutas. Porque escondido neste modelo apenas existe a opinião de juízes, e como meras opiniōes pouco servem ao objetivo de ordenar a sociedade e maximizar a felicidade. Afirma: “... enquanto nas instituiçóes não-escritas, por inexistir algum signo certo que dê testemunho de sua autoridade, sua validade, qualquer que seja sua raiz, podemos vê-la recusada [pelos juízes] sem remorso. Trata-se de uma debilidade radical ínsita a todo direito não-escrito" (Bentham, 2003, p. 17, nota "e").

Como se pode notar, a afirmação da ausência de uma autoridade que seja referência de segurança e altivez do direito está na base das consideraçôes críticas de Bentham ao modelo Common Law. Por isso sustenta que é imprescindível a existência de uma autoridade soberana que oriente os súditos de maneira clara e pública, sem a qual qualquer pretensão de orientação coletiva vê-se frustrada.

Seu argumento, assim, é simples e direto: os sujeitos não têm condiçôes de obedecer se a vontade não está expressa inteligivelmente de maneira segura. E isso apenas um regime de leis pode assegurar. Significa dizer que apenas uma norma jurídica (a law), por ser um ato de vontade emanado do soberano com as garantias da sanção, pode servir de instrumento para a consecução do bem-estar dos indivíduos. Porque sem essa referência segura não é 
possível saber o que é correto e o que não é correto e, por conseguinte, qual é a conduta esperada pelo soberano.

Enfim, o Common Law apresenta obstáculos insuperáveis à concretização de um agir racional e responsável à luz do princípio da utilidade. Portanto, tal modelo - no entendimento de Bentham - deve ser urgentemente substituído.

Estes são os defeitos por ele apontados a respeito do direito inglês:

(a) "Incerteza prescritiva": o modelo do direito comum não possibilita ao destinatário das normas (o cidadáo) ter pleno conhecimento do que deve seguir em seu dia-a-dia. Porque as práticas judiciais são pouco claras e estão adstritas ao arbítrio e à discricionariedade dos juízes.

(b) "Retroatividade na aplicação das leis": quando o juiz aplica uma lei conforme uma construçáo própria sua, ele está regulando um comportamento passado com responsabilizações retroativas.

(c) "Falta de determinação da origem das leis": a ausência de um soberano determinado (por exemplo, parlamento) que cria a totalidade das leis gera insegurança.

(d) "Falta da aplicação do princípio da utilidade": os juízes, baseando-se nos precedentes ou em técnicas de analogia, não têm uma visão adequada da criação e formação das leis, de modo que lhes faltam condiçóes de zelar, com medidas gerais, pela realização dos princípios que maximizam a felicidade.

É a partir dessas coordenadas que Bentham apresenta a sua formulação sobre o que seja uma norma jurídica. No entanto, para ser factível, ele parte de uma reconstrução do significado de norma. Daí afirmar que "uma norma jurídica é um conjunto de signos declarativos de uma vontade concebida ou adotada pelo soberano de um Estado, em relação à conduta que deve ser adotada em um caso determinado por uma pessoa ou classe de pessoas que, na situação em questão, estão sujeitas a tal poder ou se supóe que estão". E continua: "Contando como garantia do cumprimento desta vontade com a expectativa de certos ventos que são queridos, esta declaração servirá como meio para efetivar tais eventos; e a possibilidade do que é querido atuará como um motivo sobre aquele cuja conduta está em questão" (Bentham, 1970, p. 1).

\section{SOBRE AS MODALIDADES PRESCRITIVAS}

Da definiçãao anterior de norma jurídica foi possível obter uma, por assim dizer, "noção muito geral" a respeito do universo normativo jurídico retratado por Bentham. Desse universo, iremos explorar a partir de agora as suas notas mais salientes. Em síntese, estes são os pontos da investigação de Bentham: a) a "natureza" da norma e b) os "elementos da norma”.

Conforme já destacado, para ele, "uma norma jurídica é um conjunto de signos declarativos de uma vontade concebida ou adotada pelo soberano de um Estado, em relação à conduta que deve ser adotada em um caso determinado por uma pessoa ou classe de pessoas que, na situação em questão, estão sujeitas a tal poder ou se supóe que estão" (Bentham, 1970 , p. 1-2). 
De tal acepção, poder-se-ia inferir que para o autor as normas presentes em sua formulação são tão-somente as normas imperativas. Isso porque os atos de volição do soberano são atos "... em relação à conduta que deve ser adotada em um caso determinado por uma pessoa ou classe de pessoas".

Entretanto, em exame mais atento do conjunto do trabalho de Bentham, nota-se que essas normas imperativas - em que pese o fato de elas desempenharem, sob o ponto de vista funcional, atividade imprescindível para a consecução dos fins estabelecidos pelo princípio da utilidade - não estão sozinhas.

Segundo Bentham, a par das normas imperativas (que são as "normas principais" de um ordenamento jurídico), cuja finalidade é a de possibilitar que o soberano desempenhe a sua tarefa social de conformar condutas, existem outras normas, designadas de "nãoimperativas" (ou "não-coercitivas"), de atuação "funcional subsidiária" e de "eficácia dependente". São exemplos as "normas permissivas".

No entanto, e propriamente, o pano de fundo da "natureza" da norma está no dilema que identifica na procura da distinção entre a norma "penal" e a norma "civil". Este o labirinto de Bentham e centro do seu pensamento filosófico jurídico, que fez com que, notando o problema, dedicasse uma nota conclusiva em Uma introduçáo aos Princípios da Moral e da Legislação. Estas as palavras e os questionamentos de Bentham: "Onde radica a identidade e a plenitude de uma lei? Em que consiste esta distinção? Onde se situa a separação entre uma lei penal e uma lei civil? Em que consiste a distinção, e onde está a separação entre os outros braços da lei [as leis constitucionais], e a lei penal?" (Bentham, 2005, p. 8).

As normas jurídicas possuem duas partes bem nítidas: a primeira, que é a parte "diretiva", e a segunda, que é a parte "sancionadora". Aquela cumpre a função de expressar a vontade do soberano quanto a uma conduta ou ato; é, portanto, designaçáo sinônima para "ordem". A ordem é sempre diretiva positiva (uma determinação de fazer) ou uma proibição (uma determinação de não-fazer), que pode ser alterada por ordens neutras que as "neutralizam". A parte "sancionadora" é uma predição com respeito ao que ocorrerá caso a ordem do soberano não seja atendida.

Sendo assim, entende Bentham que toda e qualquer lei possui, em si mesma, uma matéria penal e uma matéria civil. A matéria civil está relacionada ao conjunto de circunstâncias que ampliam ou que limitam o ato a que se refere a lei; a matéria penal vinculase ao castigo e às circunstâncias ou previsóes que ampliam ou limitam a determinação do castigo (Bentham, 2005, p. 306).

Além das leis penais e civis, o autor acrescenta a existência das leis "constitucionais": imprescindíveis para conferir poderes e para prescrever deveres às pessoas a que são atribuídos esses poderes (Bentham, 2005, p. 307).

Assim, os poderes atribuídos pelas leis constitucionais decorrem, principalmente, da atuação das normas permissivas (ou desconectivas), isto é, normas que excepcionam leis imperativas. Mas a matéria que indica quais são os indivíduos que possuem poderes ou deveres [a definição desses agentes] é de natureza expositiva.

Em suma, em que pese o fato de a "natureza" da norma jurídica - considerando o princípio da utilidade (e vislumbrado o aspecto funcional) - ser a de expressar diretiva, podese encontrar - na literatura benthamiana - composição mais complexa e articulada do que a de simples ordens e obediência. Isso porque inexiste a disposição, em códigos separados, das "três leis" mencionadas (penais, civis e constitucionais), mas cada uma apresenta essa tripla configuração. 
Uma norma jurídica, diz Bentham, ”... é um conjunto de signos declarativos de uma vontade...”. Nesse sentido, evidencia-se o aspecto lingüístico na definição do comunicado pelo soberano. Feita a comunicação, os elementos presentes nela são de extrema importância. Com respeito aos "elementos" das normas, ao menos três aspectos devem ser referidos: os sujeitos, os destinatários e o objeto.

Uma norma possui um "sujeito ativo", que é composto por pessoas e coisas em relação às quais encontra razão de ser o ato regulado pela norma.

O "sujeito passivo" de uma norma jurídica, por seu turno, é o termo, por assim dizer, final do ato que é regulado. Por exemplo, se na previsão de homicídio o sujeito ativo é o universo de pessoas que pode realizá-lo, o sujeito passivo é o outro universo que pode sofrêlo. Pense-se naquele que embora possa "matar alguém" não comete propriamente o crime de homicídio por razóes relacionadas ao seu desenvolvimento intelectual. Embora possa não cometer o crime de homicídio, certamente pode ser vítima de um crime de homicídio. Portanto, um e outro não podem ser identificados, nem mesmo os que fazem parte do primeiro grupo integram, necessariamente, o segundo grupo.

O "objeto" da norma é, em resumo, o "ato de matar", caso seja mantido o exemplo anterior. Isto é, o "objeto" é constituído pela inteira classe de atos que possam porventura provocar a morte de alguém. Ou seja, é indiferente para a identificação de um homicídio ter sido a vítima morta por "fogo", "faca” ou "veneno". Isso significa que em todos esses casos há "homicídio", muito embora se possam imputar conseqüências mais severas para uma ou mais das situaçóes conforme a sua realização. Bentham se refere à ”... conduta que deve ser adotada em um caso determinado por uma pessoa ou classe de pessoas que, na situação em questão, estão sujeitas a tal poder”.

Finalmente, o autor faz menção às normas gerais e às normas particulares. Por "normas gerais" indica aquelas que regulam classes de sujeitos ativos e seus comportamentos e por "normas particulares", as que se referem a um determinado sujeito ativo. Por exemplo, "O sujeito $X$ não pode usar o escritório das 7 da manhã até as 13 horas".

\section{O PAPEL CENTRAL DA SANÇÃO}

Sancionar alguém não significa apenas infligir algum prejuízo, uma "dor", mas também empreender atividade custosa à comunidade inteira, tendo em vista que sancionar importa em gastar os impostos para estabelecer e concretizar a punição. Daí que punir só se justifica sob os olhos do princípio utilitarista se os benefícios estimados com a sua aplicação superarem os custos e a dor infligida no condenado. Sob essa ótica é que a ideia de sanção deve ser minimamente orientada.

Sabe Bentham que, a partir dos seus pressupostos, caso seja a pessoa razoável, aceitará o princípio da utilidade e agirá para o bem da coletividade. Mas sabe também que é possível que haja pessoas pouco razoáveis. Por isso analisou a relação entre as açóes humanas e as noçóes de prazer e de dor.

Diante desse quadro, a sanção desempenha papel de grande importância, pois entende o nosso autor que, como instrumento de prazer e de dor, constitui fator importante para determinar ou influir nos comportamentos humanos.

Por "sanção" entende, portanto, uma fonte de prazer e de dor. E se é fonte de um e de outra, é uma fonte ou origem de motivos. Pois um "motivo" é "qualquer coisa que, influenciando a vontade de um ser sensível, se supóe servir como meio de determiná-lo 
a agir, ou voluntariamente deixar de agir, em qualquer determinada ocasião". Não é que todo e qualquer motivo seja uma sanção; o é, apenas, a que confere força obrigatória a uma conduta.

Assim, há quatro tipos de sanção possíveis: 1) a sanção física, 2) a sanção política, 3) a sanção moral e 4) a sanção religiosa (Bentham, 2005, p. 31-32).

(1) "Sanção física": "Se o prazer ou a dor têm lugar ou se esperam na vida presente e no curso ordinário da natureza, não propositalmente modificado pela interposição da vontade de algum ser humano nem por alguma interposição extraordinária de algum ser invisível superior, podemos dizer que tal prazer ou tal dor derivam da - ou têm razão com a - sanção física".

(2) "Sanção política": "Se o prazer ou a dor têm lugar ou se esperam de pessoa particular ou de um grupo de pessoas na comunidade, as quais, sob nomes correspondentes ao de juiz, são escolhidas para os objetivos específicos de administrar, de acordo com a vontade do poder soberano ou supremo de governo existente no Estado, podemos dizer que o prazer e a dor dimanam da sanção política".

(3) "Sanção moral": "Se o prazer e a dor estiverem nas mãos de pessoas que por acaso ocupam um lugar de destaque na comunidade, segundo a disposição espontânea de cada pessoa, e não de acordo com alguma regra estabelecida ou acordada, podemos dizer que o prazer e a dor derivam da sanção moral ou particular".

(4) "Sanção religiosa": "Se dependerem da mão imediata de um ser superior invisível, quer na presente vida, quer em uma vida futura, pode-se dizer que derivam da sanção religiosa”.

Em outras palavras, por sanção "física" Bentham aponta a dor e o prazer que decorrem dos impulsos e restriçóes que derivam das circunstâncias naturais; por sanção "política", aquela aplicada pela autoridade política na forma de castigos e de prêmios; por sançáo "moral" (ou popular), a que resulta da opiniáo coletiva, isto é, como consequência da aprovação ou da desaprovação das pessoas com as quais o agente tem contato; e por sanção "religiosa", a que emana da crença ou da esperança de prêmios e por temor do castigo divino.

Destas quatro sanções, apenas três são concebíveis em relação a seres inteligentes e dotados de vontade: as sançóes política, moral e religiosa. Sendo que a principal é a sanção "política," ao passo que a sanção moral e a religiosa são coadjuvantes ou, como quer Bentham, "auxiliares".

No entanto, há casos em que não tem cabimento punir. Porque as sanções apenas devem ser utilizadas quando o seu uso abre chances para se evitar um mal maior. Basicamente são quatro essas situaçóes: 1) quando não houver motivos para a punição (ou seja, quando inexistir prejuízo a ser evitado); 2) quando ela não puder ser eficaz (quando não age de modo a evitar o prejuízo maior); 3) quando for inútil ou excessivamente dispendiosa (o que acontece quando a aplicaçáo da sançáo provoca um prejuízo maior à coletividade do que não aplicá-la); e, por último, 4) quando for supérflua (o que acontece se o prejuízo puder ser evitado com outra medida). 


\title{
10. CONCLUSÃO
}

$\mathrm{Na}$ distinção entre o direito como "é" (doutrina expositiva) e o direito como "possibilidade futura" (doutrina crítica), Bentham explicita sua convicção sobre a possibilidade de se criar - com base no princípio da utilidade - uma sociedade disciplinada cujo objetivo é a maximização dos benefícios para a coletividade. Compreendendo a ação humana e as noçóes de "prazer" e de "dor" como referências de determinação do agir, a sanção e o dever assumem posições de relevo em sua formulação teórico-jurídica. Pois, para Bentham, o utilitarismo informa o fim a ser alcançado com a aplicação das sançóes e esta dimensão é delimitada em termos de "legal" e "ilegal" através das normas jurídicas. O soberano, nesse contexto, assume posição central: porque é da vontade do soberano (seja por emissão direta, pela "adoção por recepção" ou pela "adoção por pré-adoção") que as normas (as leis) são identificadas como conjuntos de signos declarativos de vontade e dadas a conhecer aos cidadáos pelos atos das autoridades. $\mathrm{O}$ direito, na síntese da teoria de Bentham, deve possuir, assim, expressiva conotação pragmática, tendo em atenção que a sua razão última é a de aumentar a felicidade de todos e desestimular as açóes que possam gerar conseqüências negativas para a comunidade. $\mathrm{Na}$ base da sua formulação, o desejo de transformar, com o utilitarismo, a ética em uma ciência da sociedade e do governo.

\section{REFERÊNCIAS BIBLIOGRÁFICAS}

\section{Hart, H. L. A. (2001). The Demystification of the Law. In Essays on Bentham: Studies} in Jurisprudence and Political Theory. Oxford: Clarendon Press.

Bentham, J. (1970). Of Laws in General. New York: Oxford University Press.

Bentham, J. (2003). Un fragmento sobre el gobierno. Madrid: Tecnos.

Bentham, J. (2005). An Introduction to the Principles of Moral and Legislation. Oxford: Clarendon Press.

Dinwiddy, J. (2004). Bentham (select writings). California: Stanford University Press.

\begin{abstract}
Adrian Sgarbi
adriansgarbi@gmail.com

ADRIAN SGARBI é docente de dedicação exclusiva de Teoria do Direito da Pontifícia Universidade Católica do Rio de Janeiro nos cursos de Graduação, Mestrado e Doutorado; Visiting Professor da Universidat de Girona, España/Cataluña (2010-) e pesquisador permanente da Cátedra de Cultura Jurídica (Universitat de Girona, España). Doutor e PósDoutor em Direito pela Universidade de São Paulo (USP, 2002; 2007-2009), Bacharel e Mestre pela Pontifícia Universidade Católica do Rio de Janeiro (PUC-Rio, 1994 e 1997). Como pesquisador, tem centrado esforços no exame das fundaçóes do pensamento jurídico atual e na composição de uma teoria jurídica que se ocupa dos fenômenos pragmáticos. É autor, dentre outros trabalhos, de: "O Referendo" (Rio de Janeiro, Renovar, 1999, 402 p.), "Clássicos de Teoria do Direito", 2a. Edição, Revista e Ampliada (Rio de Janeiro, Lumen Juris, 2009, 238 p.), "Hans Kelsen (Ensaios Introdutórios)” (Rio de Janeiro, Lumen Juris, 2007, 167 p.), "Teoria do Direito (Primeiras liçôes)" (Rio de Janeiro, Lumen Juris, 2007, 753 p.) e "Introdução à Teoria do Direito" (Edição Europeia, 2012, 382 p.; Edição Brasileira, 2013,
\end{abstract}


381 p.). Representante da Cátedra de Cultura Jurídica (Universitat de Girona, España), no Brasil; Diretor da Coleção "Filosofia e Direito" (Brasil) e da Coleção "Filosofía y Derecho" (España, conjuntamente com José Juan Moreso e Jordi Ferrer Beltrán), Marcial Pons; Membro do Scientific Commitee da Revista "Analisi e Diritto" (Itália); Membro do Corpo Editorial da Revista "Arquivos do Ministério da Justiça” (Ministério da Justiça/Brasília) e da Revista "Direito, Estado, Sociedade (PUC-Rio)". Referee da Revista "Ciência Hoje" e reviewer da Beijing Law Review (China). Autor do blog Pesquisatec (www.pesquisatec. com). Tem experiência na área de Direito, atuando principalmente nos seguintes temas: Teoria do Direito, Teoria da Legislação e Interpretação dos Documentos Normativos. 